\title{
SECAGEM DE SEMENTES DE SOJA EM SILO COM DISTRIBUIÇÃO RADIAL DO FLUXO DE AR. I. MONITORAMENTO FÍSICO'
}

\author{
LUIZ CARLOS MIRANDA² ${ }^{2}$ WALTER RODRIGUES DA SILVA ${ }^{3}$ e CLÁUDIO CAVARIANI ${ }^{4}$
}

\begin{abstract}
RESUMO - O trabalho foi desenvolvido com o objetivo de avaliar a evolução física do processo de remoção de água das sementes em secador estacionário, com cilindro central perfurado e distribuição radical de ar. A pesquisa foi conduzida com sementes de soja, variando o fluxo $\left(26,9,28,4\right.$ e $\left.33,2 \mathrm{~m}^{3} / \mathrm{minuto} / \mathrm{t}\right)$ e a temperatura do ar insuflado $\left(42,46\right.$ e $\left.50^{\circ} \mathrm{C}\right)$, considerando a posição das sementes $(17,34$ e $51 \mathrm{~cm}$ em relação ao cilindro de insuflação) e o tempo de secagem (zero a doze horas, com intervalos de duas horas). Foram caracterizados o ar ambiente, o ar insuflado, as temperaturas e os teores de água da massa, as velocidades e curvas de secagem. As avaliações realizadas destacaram vantagens físicas operacionais da combinação de $28,4 \mathrm{~m}^{3} /$ minuto/t com $46^{\circ} \mathrm{C}$ e o contrário, com a combinação de $26,9 \mathrm{~m}^{3} /$ minuto $/ \mathrm{t}$ com $42^{\circ} \mathrm{C}$
\end{abstract}

Termos para indexação: processamento, desidratação.

\section{DRYING OF SOYBEAN SEEDS IN A RADIAL AIR FLOW DRYER. I. PHYSICAL MONITORING}

\begin{abstract}
The purpose of this research was to study several physical parameters of soybean seed drying submitted to stationary process with radial air distribution by combining different air flows $\left(26.9,28.4\right.$ and $33.2 \mathrm{~m}^{3} /$ minute/ton) and temperatures $\left(42,46\right.$ and $\left.50^{\circ} \mathrm{C}\right)$, considering seed positions in the seed mass $(17,34$ and $51 \mathrm{~cm}$ in relation to the insuflation cylinder) and drying periods (zero to twelve hours with two-hour intervals). Environmental air, insuflation air, seed temperatures, moisture content of seeds, drying speed and drying curves were characterized. Considering the evaluated parameters during the drying process, the physical advantages of the combination of $28.4 \mathrm{~m}^{3} /$ minute/ton with $46^{\circ} \mathrm{C}$, and the desadvantage of the combination of $26.9 \mathrm{~m}^{3} /$ minute/ton with $42^{\circ} \mathrm{C}$ were observed.
\end{abstract}

Index terms: processing, dehydration.

\section{INTRODUÇ̃̃O}

Os métodos de secagem são denominados quanto à utilização de equipamentos (secagem natural ou artificial), quanto à exposição ao calor (secagem

1 Aceito para publicação em 6 de novembro de 1998. Extraído da Tese de Doutorado do primeiro autor, apresentada à USP-ESALQ, Piracicaba, SP

${ }^{2}$ Eng. Agr., Dr., Embrapa-Serviço de Negócios para Transferência de Tecnologia (SNT), Caixa Postal 231, CEP 86001-970 Londrina, PR. E-mail: miranda@cnpso.embrapa.br

${ }^{3}$ Eng. Agr., Dr., USP, Escola Superior de Agricultura 'Luiz de Queiroz', Caixa Postal 09, CEP 13418-900 Piracicaba, SP. E-mail: wrsilva@carpa.ciagri.usp.br

${ }^{4}$ Eng. Agr., Dr., Prof. Assistente, UNESP, Faculdade de Ciências Agronômicas, Caixa Postal 237, CEP 18603-970 Botucatu, SP. E-mail: secdamv@fca.unesp.br contínua ou intermitente), e quanto à movimentação das sementes (secagem estacionária ou contínua) (Kreyger, 1973; Brooker et al., 1974; Lasseran, 1979; Silva et al., 1983; Carvalho, 1994).

Nos métodos de secagem artificial, a fonte térmica pode ser variável. O que caracteriza o método como artificial é o fato de que, praticamente todo o processo é executado com o auxílio de aparelhos mecânicos, elétricos ou eletrônicos e o ar é forçado através da massa de sementes. Este é o tipo de secagem que mais freqüentemente se adapta aos esquemas de produção de sementes, tendo em vista a rapidez com que remove quantidades elevadas de água; é a opção mais freqüentemente adotada, inclusive, na produção de grãos.

O método estacionário consiste, basicamente, em forçar a passagem do ar através da massa de semen- 
tes que permanece em repouso. São importantes as precauções para evitar a supersecagem da camada de sementes mais próxima à entrada de ar aquecido e, ao mesmo tempo, permitir a retirada de água na camada mais distante, para que não seja acelerada a deterioração das sementes.

A secagem, nos silos estacionários de fundo falso perfurado, se processa da base para a superfície da massa de sementes e, nos de tubo central perfurado, do centro para a periferia; ocorre em camadas, em função da formação de zonas de secagem correspondentes às regiões de intercâmbio de água entre a semente e o ar. McLean (1980) ponderou que em secadores com distribuição radial do ar, a reduzida espessura da massa de sementes, em associação com características aerodinâmicas favoráveis, faz com que a pressão estática seja baixa, o que possibilita a utilização de fluxos de ar próximos a $30 \mathrm{~m}^{3} /$ minuto/t.

O fluxo de ar deve ser suficiente para não ficar saturado antes de deixar a massa de sementes (Brandenburg et al., 1961), podendo ser aumentado enquanto seja capaz de absorver toda a água liberada pelas sementes. A partir deste ponto, a migração hídrica, do interior para a superfície de cada semente, torna-se o principal fator a influenciar a velocidade de secagem.

O modo como se processa a secagem estacionária origina gradientes de temperatura e de umidade na massa (Brooker et al., 1974; McLean, 1980; Corrêa, 1981; Cavariani \& Baudet, 1982; Pasin, 1991). Em secador estacionário com distribuição radial de ar, sob temperatura de $42^{\circ} \mathrm{C}$, Corrêa (1981) não observou diferenças entre as temperaturas das sementes de arroz mais próximas ao tubo central e as das mais afastadas. Contrariamente, Pasin (1991), em soja, constatou gradientes de até $15^{\circ} \mathrm{C}$ em secadores similares. O gradiente do teor de água, entre sementes diferentemente distanciadas em relação à zona de entrada do ar, depende da umidade relativa, da temperatura, do fluxo do ar, do teor de água, da espessura da massa e da capacidade de transferência de água das sementes para o ar. Esse gradiente é reduzido com diminuições na temperatura e na espessura da massa de sementes e elevação do fluxo de ar. Nas camadas mais distantes da entrada do ar, pode ocorrer aumento do teor de água das sementes em conseqüência da condensação provocada pela passagem do ar úmido por camadas com temperatura mais baixa (Brooker et al., 1974).

Brooker et al. (1974) ressaltaram que temperaturas da massa de sementes situadas entre $40,5^{\circ} \mathrm{C}$ e $43,3^{\circ} \mathrm{C}$ são consideradas como máximas, e acima delas podem ser gerados danos físicos ou químicos. No entanto, a diferença entre a temperatura do ar insuflado e a da massa de sementes depende do tipo de secador, da espécie botânica considerada, e da resistência ao movimento do ar; torna-se necessário conhecer o comportamento do calor em cada tipo de secador e em cada espécie. Segundo Harrington (1972), sementes mais úmidas são mais suscetíveis aos danos térmicos, razão pela qual sugeriu que, quanto maior o teor de água, menor deve ser a temperatura empregada. Porém, Brandenburg et al. (1961) ponderaram que a água superficial pode ser retirada sob alta temperatura do ar, uma vez que o processo de evaporação remove calor suficientemente, não alterando a temperatura das sementes. Abaixo de $30 \%$ de água, no entanto, a quantidade de água, para evaporação fica menos disponível, e a temperatura da massa tende a aumentar.

Apesar das vantagens que apresenta, a secagem é uma operação potencialmente danosa à qualidade das sementes; a magnitude do dano depende dos corretos manejos dos teores de água inicial e final do produto, da temperatura, da umidade relativa, do fluxo de ar, da taxa de secagem e do período de exposição ao ar aquecido. A secagem de sementes de soja (Glycine max (L.) Merrill) é particularmente dificultada por suas características morfológicas e composição química.

Os secadores estacionários, com cilindro central perfurado e distribuição radial de ar, têm-se apresentado como uma das opções para essa operação. A presente pesquisa objetivou avaliar a evolução física do processo de remoção de água das sementes nesse tipo de secador.

\section{MATERIAL E MÉTODOS}

Foram utilizadas sementes de soja da cultivar EMBRAPA 4 (BR 4 RC), produzidas na safra 1994/95, em Ponta Grossa, PR. As sementes foram colhidas em dias consecutivos, de modo que o material pudesse ser processado (pré-limpeza com aproveitamento da fração 
retida entre as peneiras com crivos circulares de $8 \mathrm{~mm}$ e oblongos de 4,5 x $19 \mathrm{~mm}$ ) e encaminhado para secagem em prazo inferior a 12 horas. As secagens foram realizadas em silo estacionário com cilindro central perfurado e distribuição radial de ar, da marca Rota (mod. RC.10), com capacidade nominal para 7,5 t. O fornecimento de calor foi feito através de uma fornalha da marca Casp, de fogo direto $(70.000 \mathrm{kcal} /$ hora $)$, acoplada a ventilador centrífugo $(10 \mathrm{cv})$ dotado de polias intercambiáveis para possibilitar alterações de rotação e, conseqüentemente, de fluxo de ar.

Foram empregados três fluxos $(26,9,28,4$ e $33,2 \mathrm{~m}^{3} /$ minuto $\left./ \mathrm{t}\right)$ e três temperaturas $\left(42,46\right.$ e $\left.50^{\circ} \mathrm{C}\right)$ do ar de secagem, estudando-se a evolução física do processo considerando-se as distâncias da massa em relação ao cilindro central de insuflação do ar e períodos de secagem.

Cada combinação entre a temperatura e fluxo do ar insuflado constituiu uma secagem isolada com duração ininterrupta de 12 horas. A temperatura foi avaliada com o emprego de termômetro analógico instalado no duto de entrada do ar, e o fluxo foi calculado a partir do registro da velocidade do ar com anemômetro axial marca Lutron (mod. AM 4201), posicionado no centro do duto de entrada do ar, de acordo com a seguinte equação:

$$
\begin{aligned}
& \mathrm{F}=15 \times \mathrm{p} \mathrm{D}^{2} \times \mathrm{V}^{-1} \mathrm{M}^{-1} \\
& \text { onde: } \\
& \text { F: fluxo do } \operatorname{ar}\left(\mathrm{m}^{3} / \text { minuto } / \mathrm{t}\right) ; \\
& \text { D: diâmetro do duto de } \operatorname{ar}(\mathrm{m}) \text {; } \\
& \text { V: velocidade do } \operatorname{ar}(\mathrm{m} / \mathrm{s}) ; \\
& \text { M:massa das sementes }(\mathrm{t}) \text {. }
\end{aligned}
$$

A coleta das sementes, realizada durante a secagem, com o emprego de amostrador duplo septado desenvolvido para o experimento, considerou três distâncias $(17 \mathrm{~cm}$, $34 \mathrm{~cm}$ e $51 \mathrm{~cm}$ ) radiais em relação ao cilindro central de insuflação de ar. Cada distância foi representada pela reunião de subamostras coletadas em três alturas eqüidistantes $1,70 \mathrm{~m}$ entre si. A primeira altura situou-se a $0,70 \mathrm{~m}$ da base do secador; a segunda, a $2,40 \mathrm{~m}$; a terceira, a 4,10 m. As repetições foram definidas pela subdivisão axial do secador em três partes.

Durante a secagem, as coletas de sementes foram realizadas em intervalos de duas horas, para o monitoramento físico da secagem, quando foram obtidos os seguintes dados: temperatura e umidade relativa do ar ambiente, determinadas a partir de dados obtidos em termohigrógrafo instalado externamente ao secador; pressão de vapor e umidade relativa do ar insuflado, calculadas a partir dos dados de temperatura e umidade relativa do ar ambiente, de temperatura do ar insuflado e de temperatura do ponto de orvalho, pelo programa para determinar propriedades psicrométricas (Biagi \& Silva, 1990) considerando a pressão barométrica local de $668 \mathrm{~mm}$ de mercúrio; pressão estática ( $\mathrm{mm} \mathrm{ca}$ ) do ar insuflado, determinada pelo tubo-de-Pitot, conectado em um ponto frontal em posição oposta à da entrada do ar aquecido na câmara de plenum da base do secador; temperatura da massa de sementes, obtida com aparelho digital da marca Entag, equipado com pares termoelétricos, com leituras em todos os pontos de amostragem das sementes; a temperatura referente a cada uma das três distâncias consideradas em relação ao tubo central de insuflação de ar foi representada pela média das temperaturas obtidas nas três alturas correspondentes; a variação da temperatura $\left({ }^{\circ} \mathrm{C}\right)$ na massa de sementes, representada pela diferença entre as temperaturas encontradas nas distâncias de $17 \mathrm{~cm} \mathrm{e} 51 \mathrm{~cm}$; o teor (\%) de água das sementes, determinado pelo método de estufa a $105^{\circ} \mathrm{C} \pm 3^{\circ} \mathrm{C}$, durante 24 horas, conforme Brasil (1992); o teor (\%) de água médio ponderado da massa de sementes, calculado a partir dos dados obtidos nas três distâncias e considerando a representatividade relativa, de cada distância (distância de $17 \mathrm{~cm}, 30 \%$; distância de $34 \mathrm{~cm}, 30 \%$; distância de $51 \mathrm{~cm}, 40 \%$ ), no volume ocupado pela massa de sementes; a variação do teor (\%) de água na massa de sementes, calculada pela diferença entre os teores de água obtidos nas amostras de sementes relativas às distâncias de $17 \mathrm{~cm}$ e $51 \mathrm{~cm}$; a velocidade média de secagem $\left(\% \mathrm{H}_{2} \mathrm{O} /\right.$ hora $)$, estimando a remoção de água das sementes nas três distâncias, por unidade de tempo, foi calculada através do quociente da diferença entre os teores inicial e final de água das sementes, pelo tempo total (12 horas) de secagem; a velocidade média ponderada de secagem $\left(\% \mathrm{H}_{2} \mathrm{O} /\right.$ hora $)$ da massa de sementes, utilizando a velocidade média de secagem encontrada em cada distância, foi calculada levando-se em conta a participação relativa de cada distância no volume ocupado pela massa de sementes; as curvas de secagem, determinadas por meio do ajuste de regressão polinomial, relacionando o teor de água das sementes e o tempo de secagem, nas três distâncias.

\section{RESULTADOS E DISCUSSÃO}

Os dados do ar ambiente, do ar insuflado e da temperatura da massa de sementes são apresentados nas Tabelas 1,2 e 3.

As temperaturas do ar insuflado revelaram-se próximas às desejadas, provavelmente pela reduzida 
TABELA1. Dados do ar ambiente, do ar insuflado e da massa de sementes de soja obtidos durante secagens estacionárias conduzidas sob $42^{\circ} \mathrm{C}$ com variações no fluxo do ar insuflado. Ponta Grossa, PR, $1995^{1}$.

\begin{tabular}{|c|c|c|c|c|c|c|c|c|c|c|}
\hline \multirow{3}{*}{$\begin{array}{c}\text { Fluxo } \\
\left(\mathrm{m}^{3} / \mathrm{minuto} / \mathrm{t}\right)\end{array}$} & \multirow{3}{*}{$\begin{array}{l}\text { TS } \\
\text { (h) }\end{array}$} & \multicolumn{2}{|c|}{ Ar ambiente } & \multicolumn{4}{|c|}{ Ar insuflado } & \multirow{2}{*}{\multicolumn{3}{|c|}{$\begin{array}{c}\text { Temperatura das sementes }\left({ }^{\circ} \mathrm{C}\right) \\
\text { Distâncias }(\mathrm{cm})\end{array}$}} \\
\hline & & \multirow{2}{*}{$\begin{array}{c}\mathrm{T} \\
\left({ }^{\circ} \mathrm{C}\right)\end{array}$} & \multirow{2}{*}{$\begin{array}{l}\mathrm{UR} \\
(\%)\end{array}$} & \multirow{2}{*}{$\begin{array}{c}\mathrm{T} \\
\left({ }^{\circ} \mathrm{C}\right)\end{array}$} & \multirow{2}{*}{$\begin{array}{l}\text { UR } \\
(\%)\end{array}$} & \multirow{2}{*}{$\begin{array}{l}\mathrm{PV} \\
(\mathrm{kPa})\end{array}$} & \multirow{2}{*}{$\begin{array}{c}\mathrm{PE} \\
\text { (mm ca) }\end{array}$} & & & \\
\hline & & & & & & & & 17 & 34 & 51 \\
\hline \multirow[t]{7}{*}{26,9} & 0 & 23,0 & 78,0 & 21,7 & 84,4 & 2,2 & 30,0 & 22,3 & 22,5 & 22,0 \\
\hline & 2 & 23,0 & 71,0 & 43,0 & 23,1 & 2,0 & 30,0 & 31,5 & 27,1 & 26,5 \\
\hline & 4 & 24,0 & 68,0 & 42,0 & 24,8 & 2,0 & 30,0 & 36,6 & 27,3 & 26,7 \\
\hline & 6 & 26,0 & 62,0 & 41,7 & 25,8 & 2,1 & 30,0 & 39,9 & 29,4 & 26,5 \\
\hline & 8 & 26,0 & 68,0 & 42,7 & 26,9 & 2,3 & 30,0 & 39,8 & 32,8 & 25,6 \\
\hline & 10 & 25,0 & 62,0 & 41,8 & 24,2 & 2,0 & 30,0 & 39,6 & 35,3 & 26,7 \\
\hline & 12 & 25,0 & 70,0 & 41,2 & 28,2 & 2,2 & 30,0 & 38,4 & 34,8 & 26,6 \\
\hline \multirow[t]{7}{*}{28,4} & 0 & 21,0 & 69,0 & 22,7 & 62,2 & 1,7 & 30,0 & 23,1 & 23,2 & 21,8 \\
\hline & 2 & 21,0 & 61,0 & 42,2 & 18,3 & 1,5 & 30,0 & 35,1 & 25,7 & 25,2 \\
\hline & 4 & 23,0 & 60,0 & 42,0 & 20,6 & 1,7 & 30,0 & 38,1 & 30,0 & 25,2 \\
\hline & 6 & 24,0 & 60,0 & 42,4 & 21,4 & 1,8 & 30,0 & 38,8 & 34,1 & 26,3 \\
\hline & 8 & 25,0 & 60,0 & 42,1 & 23,1 & 1,9 & 30,0 & 39,6 & 35,8 & 28,3 \\
\hline & 10 & 25,0 & 62,0 & 40,4 & 26,1 & 2,0 & 30,0 & 40,0 & 36,8 & 30,4 \\
\hline & 12 & 25,0 & 71,0 & 41,4 & 28,3 & 2,2 & 30,0 & 40,8 & 37,3 & 32,1 \\
\hline \multirow[t]{7}{*}{33,2} & 0 & 21,0 & 73,0 & 21,1 & 72,5 & 1,8 & 40,0 & 21,6 & 21,7 & 20,2 \\
\hline & 2 & 21,0 & 72,0 & 41,0 & 23,1 & 1,8 & 40,0 & 37,5 & 28,2 & 26,5 \\
\hline & 4 & 22,0 & 68,0 & 42,2 & 21,7 & 1,8 & 40,0 & 39,1 & 33,9 & 26,5 \\
\hline & 6 & 24,0 & 64,0 & 40,6 & 23,5 & 1,9 & 40,0 & 39,8 & 36,5 & 29,7 \\
\hline & 8 & 27,0 & 60,0 & 42,0 & 26,1 & 2,1 & 40,0 & 41,4 & 38,6 & 33,2 \\
\hline & 10 & 28,0 & 62,0 & 40,6 & 30,8 & 2,3 & 40,0 & 40,2 & 39,0 & 34,7 \\
\hline & 12 & 28,0 & 71,0 & 41,1 & 34,3 & 2,7 & 40,0 & 39,3 & 38,0 & 35,5 \\
\hline
\end{tabular}

1 TS: tempo de secagem; T: temperatura; UR: umidade relativa; PV: pressão de vapor; PE: pressão estática; distâncias radiais em relação ao cilindro central de insuflação de ar.

oscilação da temperatura do ar ambiente durante os tratamentos de secagem. Paralelamente, os dados de pressão de vapor do ar insuflado permitiram verificar que as condições operacionais, durante as secagens, foram relativamente uniformes e sofreram reduzidas interferências climáticas externas ao secador; as diferenças observadas, dentro e entre secagens, foram ocasionais e não indicaram efeitos dos tratamentos nos dados coletados.

A diferença (1,5 $\mathrm{m}^{3} /$ minuto/t) observada entre os valores dos fluxos inferior e intermediário, pode não haver sido suficiente para promover alterações nas leituras de pressão estática no tubo-de-Pitot empregado; com isso, os valores encontrados foram idênticos nos dois casos. Contudo, quando empregado o maior fluxo, a pressão estática foi elevada, o que confirma as afirmações de Brandenburg et al. (1961) e Brooker et al. (1974) a respeito das relações entre pressão estática e fluxo de ar em secagens estacionárias. Por outro lado, fixadas as condições de fluxo e de temperatura do ar insuflado, não foi verificada qualquer alteração na pressão estática que sugerisse as variações observadas por Cavariani (1996) em milho, no espaço poroso da massa durante o processo; paralelamente, os valores máximos encontrados (40 mm ca) são indicadores de características aerodinâmicas favoráveis do equipamento, para secagem de sementes de soja proporcionadas pela reduzida espessura da massa de sementes, conforme o mencionado por McLean (1980).

Os dados de temperatura da massa permitiram verificar decréscimos à medida que era ampliada a distância das sementes ao cilindro de insuflação do ar. Para cada distância, as temperaturas cresceram, com o andamento da secagem, em magnitudes que se ampliaram com a aproximação ao cilindro de insuflação. De uma forma geral, a estabilização da temperatura da massa tendeu a ser retardada com o 
TABELA2. Dados do ar ambiente, do ar insuflado e da massa de sementes de soja obtidos durante secagens estacionárias conduzidas sob $46^{\circ} \mathrm{C}$ com variações no fluxo do ar insuflado. Ponta Grossa, PR, $1995^{1}$.

\begin{tabular}{|c|c|c|c|c|c|c|c|c|c|c|}
\hline \multirow{3}{*}{$\begin{array}{c}\text { Fluxo } \\
\left(\mathrm{m}^{3} / \text { minuto/t }\right)\end{array}$} & \multirow{3}{*}{$\begin{array}{l}\text { TS } \\
\text { (h) }\end{array}$} & \multicolumn{2}{|c|}{ Ar ambiente } & \multicolumn{4}{|c|}{ Ar insuflado } & \multirow{2}{*}{\multicolumn{3}{|c|}{$\frac{\text { Temperatura das sementes }\left({ }^{\circ} \mathrm{C}\right)}{\text { Distâncias }(\mathrm{cm})}$}} \\
\hline & & \multirow{2}{*}{$\begin{array}{c}\mathrm{T} \\
\left({ }^{\circ} \mathrm{C}\right)\end{array}$} & \multirow{2}{*}{$\begin{array}{l}\text { UR } \\
(\%)\end{array}$} & \multirow{2}{*}{$\begin{array}{c}\mathrm{T} \\
\left({ }^{\circ} \mathrm{C}\right)\end{array}$} & \multirow{2}{*}{$\begin{array}{l}\text { UR } \\
(\%)\end{array}$} & \multirow{2}{*}{$\begin{array}{c}\mathrm{PV} \\
(\mathrm{kPa})\end{array}$} & \multirow{2}{*}{$\begin{array}{c}\mathrm{PE} \\
(\mathrm{mm} \\
\mathrm{ca})\end{array}$} & & & \\
\hline & & & & & & & & 17 & 34 & 51 \\
\hline 26,9 & $\begin{array}{r}0 \\
2 \\
4 \\
6 \\
8 \\
10 \\
12\end{array}$ & $\begin{array}{l}23,0 \\
23,0 \\
25,0 \\
28,0 \\
29,0 \\
29,0 \\
28,0\end{array}$ & $\begin{array}{l}82,0 \\
76,0 \\
66,0 \\
60,0 \\
58,0 \\
60,0 \\
76,0\end{array}$ & $\begin{array}{l}25,2 \\
46,5 \\
45,6 \\
45,3 \\
46,1 \\
45,7 \\
47,1\end{array}$ & $\begin{array}{l}71,8 \\
20,7 \\
21,2 \\
23,3 \\
22,9 \\
24,2 \\
27,0\end{array}$ & $\begin{array}{l}2,3 \\
2,1 \\
2,1 \\
2,3 \\
2,3 \\
2,4 \\
2,9\end{array}$ & $\begin{array}{l}30,0 \\
30,0 \\
30,0 \\
30,0 \\
30,0 \\
30,0 \\
30,0\end{array}$ & $\begin{array}{l}27,7 \\
39,5 \\
41,3 \\
42,5 \\
44,1 \\
44,0 \\
45,7\end{array}$ & $\begin{array}{l}28,8 \\
30,6 \\
34,1 \\
37,7 \\
38,5 \\
40,8 \\
41,9\end{array}$ & $\begin{array}{l}26,0 \\
30,3 \\
30,4 \\
30,3 \\
31,3 \\
33,3 \\
35,9\end{array}$ \\
\hline 28,4 & $\begin{array}{r}0 \\
2 \\
4 \\
6 \\
8 \\
10 \\
12\end{array}$ & $\begin{array}{l}19,0 \\
19,0 \\
21,0 \\
23,0 \\
25,0 \\
26,0 \\
26,0\end{array}$ & $\begin{array}{l}72,0 \\
70,0 \\
54,0 \\
46,0 \\
46,0 \\
47,0 \\
56,0\end{array}$ & $\begin{array}{l}21,3 \\
44,7 \\
45,3 \\
46,3 \\
45,3 \\
45,9 \\
45,2\end{array}$ & $\begin{array}{l}62,5 \\
16,3 \\
13,8 \\
12,6 \\
15,0 \\
15,8 \\
19,5\end{array}$ & $\begin{array}{l}1,6 \\
1,5 \\
1,3 \\
1,3 \\
1,5 \\
1,6 \\
1,9\end{array}$ & $\begin{array}{l}30,0 \\
30,0 \\
30,0 \\
30,0 \\
30,0 \\
30,0 \\
30,0\end{array}$ & $\begin{array}{l}22,2 \\
35,9 \\
40,0 \\
42,1 \\
42,5 \\
43,6 \\
42,2\end{array}$ & $\begin{array}{l}22,4 \\
25,9 \\
20,8 \\
32,6 \\
36,3 \\
37,7 \\
38,8\end{array}$ & $\begin{array}{l}19,8 \\
25,5 \\
24,6 \\
24,3 \\
26,7 \\
30,0 \\
31,0\end{array}$ \\
\hline 33,2 & $\begin{array}{r}0 \\
2 \\
4 \\
6 \\
8 \\
10 \\
12\end{array}$ & $\begin{array}{l}23,0 \\
23,0 \\
24,0 \\
25,0 \\
25,0 \\
25,0 \\
25,0\end{array}$ & $\begin{array}{l}83,0 \\
81,0 \\
77,0 \\
84,0 \\
82,0 \\
84,0 \\
81,0\end{array}$ & $\begin{array}{l}22,6 \\
45,5 \\
44,0 \\
45,6 \\
46,8 \\
45,6 \\
45,7\end{array}$ & $\begin{array}{l}85,0 \\
23,2 \\
25,3 \\
27,0 \\
24,8 \\
27,0 \\
25,9\end{array}$ & $\begin{array}{l}2,3 \\
2,3 \\
2,3 \\
2,7 \\
2,6 \\
2,7 \\
2,6\end{array}$ & $\begin{array}{l}40,0 \\
40,0 \\
40,0 \\
40,0 \\
40,0 \\
40,0 \\
40,0\end{array}$ & $\begin{array}{l}22,8 \\
39,5 \\
40,8 \\
41,6 \\
43,1 \\
42,5 \\
42,1\end{array}$ & $\begin{array}{l}22,8 \\
31,2 \\
36,4 \\
38,6 \\
40,7 \\
40,7 \\
41,2\end{array}$ & $\begin{array}{l}21,9 \\
29,0 \\
30,2 \\
32,9 \\
35,9 \\
36,6 \\
38,3\end{array}$ \\
\hline
\end{tabular}

1 TS: tempo de secagem; T: temperatura; UR: umidade relativa; PV: pressão de vapor; PE: pressão estática; distâncias radiais em relação ao cilindro central de insuflação de ar.

aumento da distância, e os valores máximos, atingidos ao longo da secagem, foram invariavelmente inferiores aos da temperatura do ar insuflado. Especificamente na distância de $51 \mathrm{~cm}$, região de aquecimento mais lento, a elevação do fluxo favoreceu a aproximação à estabilidade que, contudo, não foi conseguida em nenhum dos tratamentos.

As variações de temperatura (Tabela 4) entre as distâncias de $17 \mathrm{~cm}$ e $51 \mathrm{~cm}$, indicativas da uniformidade térmica do processo, aumentaram, em geral, até a sexta hora operacional; a partir desse ponto, foram sendo reduzidas com o andamento da secagem. Os valores encontrados ao final do processo sugeriram que a ampliação do fluxo, independentemente da temperatura do ar insuflado, promoveu redução nos gradientes de temperatura da massa. As diferenças encontradas, situadas entre $3,8^{\circ} \mathrm{Ce} 12^{\circ} \mathrm{C}$, foram inferiores às verificadas por Pasin (1991), em soja, e superiores às constatadas, em arroz, por Corrêa (1981). A homogeneização da temperatura da massa, proveniente da mistura das sementes pelo sistema de descarga do secador é fato que, segundo McLean (1980) e Pasin (1991), colabora para evitar conseqüências danosas à conservação de massas de sementes armazenadas.

As Tabelas 5, 6 e 7 apresentam os dados do teor de água das sementes, nas três distâncias, e os valores da média ponderada na massa durante as secagens. Consistentemente, houve similaridade entre os valores obtidos na distância de $34 \mathrm{~cm}$ e os calculados para a média ponderada da massa. A retirada de água das sementes foi incrementada, em geral, como conseqüência de elevações, isoladas ou concomitantes, de fluxos e de temperaturas.

O processo de secagem ocorreu no sentido do centro para a parte externa do secador, refletindo os efeitos das variações na temperatura da massa. Assim, as diferenças observadas entre os dados do teor de água nas distâncias de $17 \mathrm{~cm}$ e $51 \mathrm{~cm}$ (Tabela 8), inicialmente crescentes com o desenvolvimento do processo, tenderam à redução ao final da operação. Contudo, as variações nos fluxos e nas 
TABELA3. Dados do ar ambiente, do ar insuflado e da massa de sementes de soja obtidos durante secagens estacionárias conduzidas sob $50^{\circ} \mathrm{C}$ com variações no fluxo do ar insuflado. Ponta Grossa, PR, $1995^{1}$.

\begin{tabular}{|c|c|c|c|c|c|c|c|c|c|c|}
\hline \multirow{3}{*}{$\begin{array}{c}\text { Fluxo } \\
\left(\mathrm{m}^{3} / \text { minuto/t }\right)\end{array}$} & \multirow{3}{*}{$\begin{array}{l}\text { TS } \\
\text { (h) }\end{array}$} & \multicolumn{2}{|c|}{ Ar ambiente } & \multicolumn{4}{|c|}{ Ar insuflado } & \multirow{2}{*}{\multicolumn{3}{|c|}{$\frac{\text { Temperatura das sementes }\left({ }^{\circ} \mathrm{C}\right)}{\text { Distâncias }}$}} \\
\hline & & \multirow{2}{*}{$\begin{array}{c}\mathrm{T} \\
\left({ }^{\circ} \mathrm{C}\right)\end{array}$} & \multirow{2}{*}{$\begin{array}{l}\text { UR } \\
(\%)\end{array}$} & \multirow{2}{*}{$\begin{array}{c}\mathrm{T} \\
\left({ }^{\circ} \mathrm{C}\right)\end{array}$} & \multirow{2}{*}{$\begin{array}{l}\text { UR } \\
(\%)\end{array}$} & \multirow{2}{*}{$\begin{array}{l}\mathrm{PV} \\
(\mathrm{kPa})\end{array}$} & \multirow{2}{*}{$\begin{array}{c}\mathrm{PE} \\
\text { (mm ca) }\end{array}$} & & & \\
\hline & & & & & & & & 17 & 34 & 51 \\
\hline \multirow[t]{7}{*}{26,9} & 0 & 23,0 & 85,0 & 24,9 & 75,8 & 2,4 & 30,0 & 25,6 & 25,7 & 24,5 \\
\hline & 2 & 23,0 & 80,0 & 49,1 & 19,1 & 2,2 & 30,0 & 41,7 & 31,7 & 31,7 \\
\hline & 4 & 25,0 & 78,0 & 50,5 & 19,6 & 2,5 & 30,0 & 46,3 & 35,8 & 31,9 \\
\hline & 6 & 25,0 & 72,0 & 52,7 & 16,2 & 2,3 & 30,0 & 49,1 & 40,9 & 32,5 \\
\hline & 8 & 27,0 & 56,0 & 49,9 & 16,3 & 2,0 & 30,0 & 47,9 & 42,7 & 32,9 \\
\hline & 10 & 29,0 & 50,0 & 49,7 & 16,5 & 2,0 & 30,0 & 49,0 & 44,2 & 34,8 \\
\hline & 12 & 29,0 & 62,0 & 50,3 & 19,9 & 2,5 & 30,0 & 48,5 & 44,3 & 36,5 \\
\hline \multirow[t]{7}{*}{28,4} & 0 & 19,0 & 80,0 & 18,2 & 84,1 & 1,8 & 30,0 & 19,4 & 19,6 & 18,0 \\
\hline & 2 & 21,0 & 68,0 & 48,0 & 15,2 & 1,7 & 30,0 & 40,4 & 27,9 & 26,7 \\
\hline & 4 & 22,0 & 64,0 & 49,2 & 14,3 & 1,7 & 30,0 & 44,3 & 33,9 & 27,6 \\
\hline & 6 & 24,0 & 60,0 & 48,6 & 15,6 & 1,8 & 30,0 & 46,3 & 38,6 & 29,3 \\
\hline & 8 & 25,0 & 60,0 & 49,4 & 15,9 & 1,9 & 30,0 & 46,0 & 41,4 & 32,3 \\
\hline & 10 & 26,0 & 60,0 & 48,6 & 17,6 & 2,0 & 30,0 & 47,8 & 42,9 & 34,1 \\
\hline & 12 & 26,0 & 66,0 & 49,9 & 18,1 & 2,2 & 30,0 & 46,8 & 44,0 & 36,1 \\
\hline \multirow[t]{7}{*}{33,2} & 0 & 23,0 & 81,0 & 22,0 & 86,0 & 2,3 & 40,0 & 21,9 & 21,9 & 21,4 \\
\hline & 2 & 23,0 & 78,0 & 49,1 & 18,6 & 2,2 & 40,0 & 42,3 & 31,0 & 29,2 \\
\hline & 4 & 25,0 & 68,0 & 49,5 & 17,9 & 2,1 & 40,0 & 43,7 & 37,1 & 29,5 \\
\hline & 6 & 27,0 & 68,0 & 48,8 & 20,9 & 2,4 & 40,0 & 43,3 & 40,2 & 32,8 \\
\hline & 8 & 27,0 & 67,0 & 50,7 & 18,7 & 2,4 & 40,0 & 45,6 & 41,7 & 36,7 \\
\hline & 10 & 27,0 & 68,0 & 49,1 & 20,6 & 2,4 & 40,0 & 46,1 & 44,2 & 39,6 \\
\hline & 12 & 27,0 & 70,0 & 49,5 & 20,8 & 2,5 & 40,0 & 45,1 & 43,7 & 40,4 \\
\hline
\end{tabular}

1 TS: tempo de secagem; T: temperatura; UR: umidade relativa; PV: pressão de vapor; PE: pressão estática; distâncias radiais em relação ao cilindro central de insuflação de ar.

temperaturas do ar insuflado não definiram, com clareza, a interferência dos tratamentos nos gradientes observados. No entanto, os dados de velocidade de secagem (Tabela 9) indicaram que a combinação entre o fluxo e a temperatura intermediários $\left(28,4 \mathrm{~m}^{3} /\right.$ minuto/t e $\left.46^{\circ} \mathrm{C}\right)$ foi a mais rápida na retirada da água, independentemente da distância considerada. Confirmando o constatado para o teor de água, as sementes da distância de $34 \mathrm{~cm}$ representaram adequadamente o comportamento da velocidade média ponderada de secagem (Tabela 9), o que sugere que a evolução do processo possa ser acompanhada na porção intermediária da massa, em concordância com o observado por Cavariani (1996).

As equações das curvas de regressão, ainda que estatisticamente significativas, indicando adequado ajuste aos dados experimentais, revelaram menor capacidade de explicação do fenômeno, com $\mathrm{R}^{2}$ inferior a 0,70 , na distância de $51 \mathrm{~cm}$ para as combina- ções de 26,9 e $33,2 \mathrm{~m}^{3} /$ minuto $/ \mathrm{t} \operatorname{com} 42^{\circ} \mathrm{C}$ (Tabela 5) e de $28,4 \mathrm{~m}^{3} /$ minuto/t com $50^{\circ} \mathrm{C}$ (Tabela 7 ). Provavelmente, o fato foi decorrente da reduzida variação entre os teores de água (Tabelas 5, 6 e 7), obtidos na distância de $51 \mathrm{~cm}$ no início do processo, que sugeriu demora na chegada da frente de secagem a essa região da massa. O avanço da frente de secagem é determinado principalmente pelo fluxo de ar empregado (Boyd et al., 1974; Zimmer, 1989) e relaciona-se com a velocidade de remoção de água das sementes. Observou-se que as relações entre o teor de água das sementes e o tempo de secagem foram representadas, na maior parte dos casos, por funções lineares independentemente das combinações de fluxos com temperaturas e das distâncias à superfície de injeção do ar aquecido na massa. A linearidade observada é consoante com os resultados encontrados por Bounous (1986), Vega (1989) e Villela (1991) que, entretanto, utilizaram método intermitente para o fornecimento do calor. 
TABELA 4. Variações entre as temperaturas $\left({ }^{\circ} \mathrm{C}\right)$ nas distâncias de $17 \mathrm{~cm}$ e $51 \mathrm{~cm}$ da massa de sementes de soja durante secagens estacionárias com diferentes fluxos e temperaturas do ar insuflado. Ponta Grossa, PR, 1995.

\begin{tabular}{ccrrrrrr}
\hline \multirow{2}{*}{$\begin{array}{c}\text { Temperatura } \\
\left({ }^{\circ} \mathrm{C}\right)\end{array}$} & $\begin{array}{c}\text { Fluxo } \\
\left(\mathrm{m}^{3} / \text { minuto/t) }\right.\end{array}$ & 2 & \multicolumn{1}{c}{ Tempo de secagem (hora) } \\
\cline { 3 - 7 } & 26,9 & 5,0 & 9,9 & 13,4 & 14,2 & 12,9 & 11,8 \\
& 28,4 & 9,9 & 12,9 & 12,5 & 11,3 & 9,6 & 8,7 \\
& 33,2 & 11,0 & 12,6 & 10,1 & 8,2 & 5,5 & 3,8 \\
& 26,9 & 9,2 & 10,9 & 12,2 & 12,8 & 10,7 & 9,8 \\
46 & 28,4 & 10,4 & 15,4 & 17,8 & 15,8 & 13,6 & 11,2 \\
& 33,2 & 10,5 & 10,6 & 8,7 & 7,2 & 5,9 & 3,8 \\
& 26,9 & 10,0 & 14,4 & 16,6 & 15,0 & 14,2 & 12,0 \\
50 & 28,4 & 13,7 & 16,7 & 17,0 & 13,7 & 13,7 & 10,7 \\
& 33,2 & 13,1 & 14,2 & 10,5 & 8,9 & 6,5 & 4,7 \\
\hline
\end{tabular}

TABELA5. Teores (\%) de água das sementes de soja nas três distâncias e média ponderada, em secagens estacionárias conduzidas sob $42^{\circ} \mathrm{C}$ com variações no fluxo do ar insuflado. Ponta Grossa, PR, 1995.

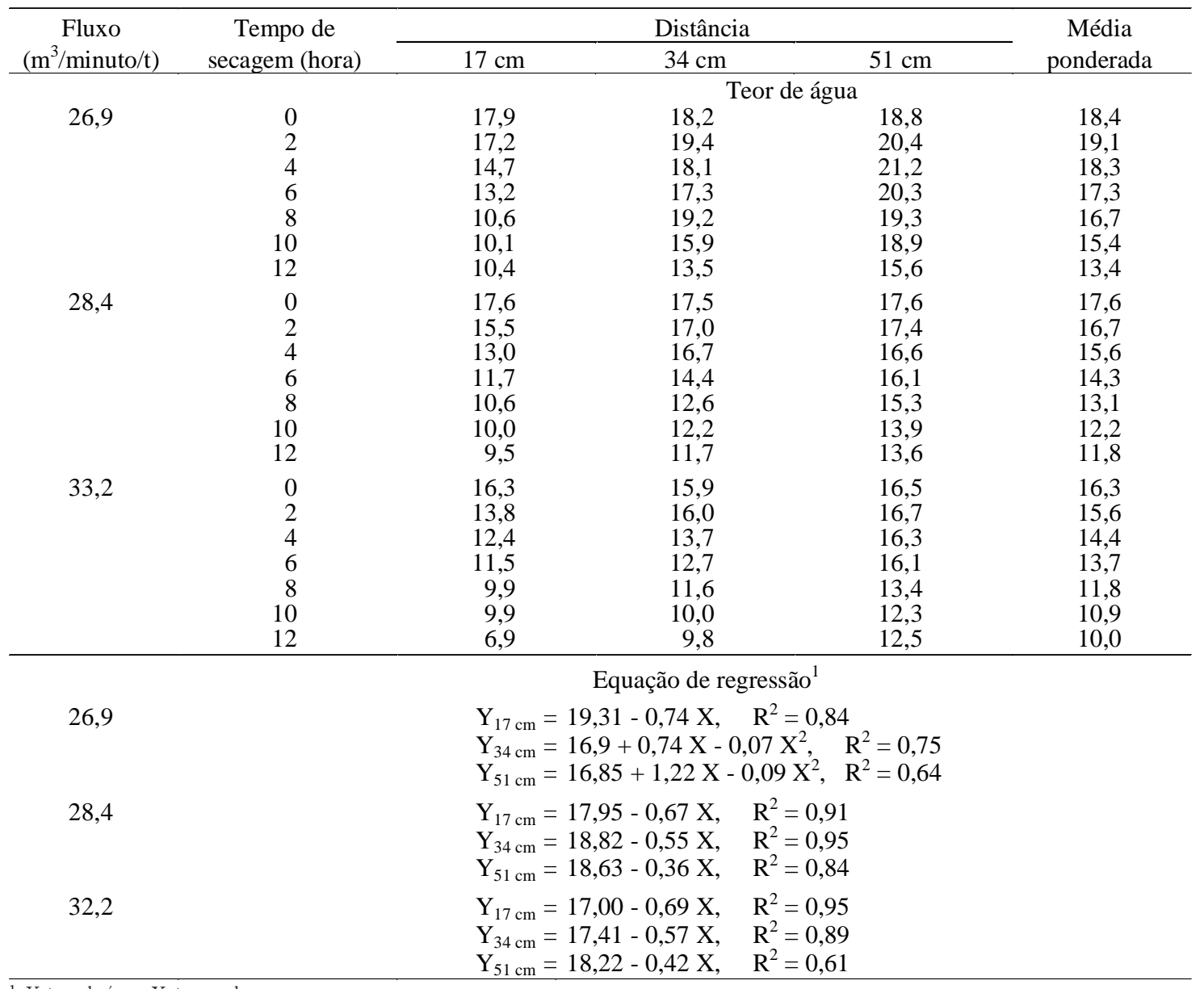


TABELA6. Teores (\%) de água das sementes de soja nas três distâncias e média ponderada, em secagens estacionárias conduzidas sob $46^{\circ} \mathrm{C}$ com variações no fluxo do ar insuflado. Ponta Grossa, PR, 1995.

\begin{tabular}{|c|c|c|c|c|c|}
\hline \multirow{2}{*}{$\begin{array}{c}\text { Fluxo } \\
\left(\mathrm{m}^{3} / \mathrm{minuto} / \mathrm{t}\right)\end{array}$} & \multirow{2}{*}{$\begin{array}{c}\text { Tempo de } \\
\text { secagem (hora) }\end{array}$} & \multicolumn{3}{|c|}{ Distância } & \multirow{2}{*}{$\begin{array}{c}\text { Média } \\
\text { ponderada }\end{array}$} \\
\hline & & $17 \mathrm{~cm}$ & $34 \mathrm{~cm}$ & $51 \mathrm{~cm}$ & \\
\hline & & \multicolumn{4}{|c|}{ Teor de água } \\
\hline \multirow[t]{7}{*}{26,9} & 0 & 16,8 & 16,2 & 15,7 & 16,2 \\
\hline & 2 & 14,3 & 15,5 & 15,4 & 15,1 \\
\hline & 4 & 12,4 & 14,8 & 15,9 & 14,5 \\
\hline & 6 & 10,8 & 12,9 & 15,1 & 13,2 \\
\hline & 8 & 9,8 & 11,8 & 13,8 & 12,0 \\
\hline & 10 & 8,8 & 10,7 & 12,9 & 11,0 \\
\hline & 12 & 9,0 & 9,4 & 11,9 & 10,3 \\
\hline \multirow[t]{7}{*}{28,4} & 0 & 19,9 & 19,9 & 20,2 & 20,0 \\
\hline & 2 & 17,9 & 19,9 & 19,5 & 19,1 \\
\hline & 4 & 14,5 & 17,7 & 19,6 & 17,5 \\
\hline & 6 & 13,5 & 16,4 & 18,2 & 16,3 \\
\hline & 8 & 11,2 & 13,7 & 16,1 & 13,9 \\
\hline & 10 & 10,8 & 13,3 & 16,5 & 13,8 \\
\hline & 12 & 7,4 & 9,4 & 11,5 & 9,6 \\
\hline \multirow[t]{8}{*}{33,2} & 0 & 16,4 & 15,6 & 16,5 & 16,2 \\
\hline & 2 & 12,9 & 14,8 & 15,7 & 14,6 \\
\hline & 4 & 11,9 & 14,2 & 15,6 & 14,1 \\
\hline & 6 & 10,9 & 11,8 & 14,0 & 12,4 \\
\hline & 8 & 10,2 & 11,1 & 14,1 & 12,0 \\
\hline & 10 & 9,5 & 10,5 & 11,6 & 10,6 \\
\hline & 12 & 8,9 & 10,1 & 10,9 & 10,1 \\
\hline & \multicolumn{5}{|c|}{ Equação de regressão $^{1}$} \\
\hline 26,9 & & \multicolumn{3}{|c|}{$\begin{array}{ll}\mathrm{Y}_{17 \mathrm{~cm}}=16,97-0,66 \mathrm{X}, & \mathrm{R}^{2}=0,88 \\
\mathrm{Y}_{34 \mathrm{~cm}}=17,78+0,59 \mathrm{X} & \mathrm{R}^{2}=0,96 \\
\mathrm{Y}_{51 \mathrm{~cm}}=17,07-0,33 \mathrm{X} & \mathrm{R}^{2}=0,79\end{array}$} & \\
\hline 28,4 & & \multicolumn{2}{|c|}{$\begin{array}{l}Y_{17 \mathrm{~cm}}=21,47-0,98 X \\
Y_{34 \mathrm{~cm}}=22,73-0,87 X \\
Y_{51 \mathrm{~cm}}=21,61-0,65 \mathrm{X}\end{array}$} & $\begin{array}{l}\mathrm{R}^{2}=0,94 \\
\mathrm{R}^{2}=0,92 \\
\mathrm{R}^{2}=0,74\end{array}$ & \\
\hline 32,2 & & \multicolumn{2}{|c|}{$\begin{array}{l}Y_{17 \mathrm{~cm}}=15,98-0,56 X \\
Y_{34 \mathrm{~cm}}=16,71-0,53 X \\
Y_{51 \mathrm{~cm}}=17,84-0,48 X\end{array}$} & $\begin{array}{l}\mathrm{R}^{2}=0,83 \\
\mathrm{R}^{2}=0,90 \\
\mathrm{R}^{2}=0,88\end{array}$ & \\
\hline
\end{tabular}

1 Y: teor de água; $\mathrm{X}$ : tempo de secagem.

Considerando as distâncias de $17 \mathrm{~cm}$ e $34 \mathrm{~cm}$, as curvas de secagem concordaram, aproximadamente, com as destacadas para operações em camadas delgadas por Kreyger (1973), Westerman et al. (1973), Brooker et al. (1974), Hall (1980) e Baker et al. (1991); contudo, apesar de haver ocorrido estabilização das temperaturas das sementes durante o processo, os dados não caracterizaram os períodos de indução e de velocidade decrescente, descritos como típicos na secagem de produtos biológicos. A inexistência do período de velocidade decrescente - indicativo de desequilíbrio entre a remoção superficial da água - e a migração do interior para a superfície das sementes foram referidas por Kreyger (1973), Brooker et al. (1974), Hall (1980), Villela (1991) e Cavariani (1996). O volume de produto significativamente elevado, e a reduzida diferença relativa entre os teores inicial e final de água são aspectos que devem ter concorrido para a aparente discordância entre as curvas obtidas e a curva típica de secagem; as 
TABELA7. Teores (\%) de água das sementes de soja nas três distâncias e média ponderada, em secagens estacionárias conduzidas sob $50^{\circ} \mathrm{C}$ com variações no fluxo do ar insuflado. Ponta Grossa, PR, 1995.

\begin{tabular}{|c|c|c|c|c|c|}
\hline \multirow{2}{*}{$\begin{array}{c}\text { Fluxo } \\
\left(\mathrm{m}^{3} / \text { minuto } / \mathrm{t}\right)\end{array}$} & \multirow{2}{*}{$\begin{array}{c}\text { Tempo de } \\
\text { secagem (hora) }\end{array}$} & \multicolumn{3}{|c|}{ Distância } & \multirow{2}{*}{$\begin{array}{c}\text { Média } \\
\text { ponderada }\end{array}$} \\
\hline & & $17 \mathrm{~cm}$ & $34 \mathrm{~cm}$ & $51 \mathrm{~cm}$ & \\
\hline & & \multicolumn{4}{|c|}{ Teor de água } \\
\hline \multirow[t]{7}{*}{26,9} & 0 & 16,3 & 16,7 & 16,6 & 16,5 \\
\hline & 2 & 14,9 & 16,5 & 17,1 & 16,3 \\
\hline & 4 & 12,3 & 15,9 & 17,2 & 15,3 \\
\hline & 6 & 11,2 & 13,7 & 17,3 & 14,4 \\
\hline & 8 & 9,7 & 12,0 & 15,9 & 12,9 \\
\hline & 10 & 9,6 & 11,8 & 15,1 & 12,5 \\
\hline & 12 & 8,5 & 10,7 & 13,8 & 11,3 \\
\hline \multirow[t]{7}{*}{28,4} & 0 & 18,1 & 18,0 & 18,6 & 18,3 \\
\hline & 2 & 15,5 & 17,4 & 17,7 & 16,9 \\
\hline & 4 & 12,6 & 15,9 & 17,3 & 15,5 \\
\hline & 6 & 11,2 & 14,6 & 16,8 & 14,5 \\
\hline & 8 & 10,2 & 12,6 & 15,3 & 13,0 \\
\hline & 10 & 9,7 & 12,7 & 15,1 & 12,8 \\
\hline & 12 & 9,2 & 11,9 & 13,2 & 11,6 \\
\hline \multirow[t]{7}{*}{33,2} & 0 & 17,3 & 18,2 & 18,0 & 17,9 \\
\hline & 2 & 15,0 & 17,2 & 17,6 & 16,7 \\
\hline & 4 & 13,2 & 15,2 & 17,0 & 15,3 \\
\hline & 6 & 12,1 & 13,2 & 16,1 & 14,0 \\
\hline & 8 & 10,5 & 12,2 & 14,3 & 12,5 \\
\hline & 10 & 10,1 & 11,3 & 12,5 & 11,4 \\
\hline & 12 & 9,1 & 10,5 & 12,5 & 10,9 \\
\hline
\end{tabular}

Equação de regressão ${ }^{1}$

26,9

$\mathrm{Y}_{17 \mathrm{~cm}}=16,99-0,65 \mathrm{X}, \quad \mathrm{R}^{2}=0,91$

$\mathrm{Y}_{34 \mathrm{~cm}}=18,24-0,55 \mathrm{X} \quad \mathrm{R}^{2}=0,91$

$\mathrm{Y}_{51 \mathrm{~cm}}=15,71+0,55 \mathrm{X}-0,05 \mathrm{X}^{2} \quad \mathrm{R}^{2}=0,84$

28,4

$\mathrm{Y}_{17 \mathrm{~cm}}=18,18-0,73 \mathrm{X}, \quad \mathrm{R}^{2}=0,87$

$Y_{34 \mathrm{~cm}}=19,06-0,53 X, \quad R^{2}=0,83$

$\mathrm{Y}_{51 \mathrm{~cm}}=19,66-0,41 \mathrm{X}, \quad \mathrm{R}^{2}=0,63$

32,2

$\mathrm{Y}_{17 \mathrm{~cm}}=17,81-0,67 \mathrm{X}, \quad \mathrm{R}^{2}=0,92$

$\mathrm{Y}_{34 \mathrm{~cm}}=19,38-0,68 \mathrm{X}, \quad \mathrm{R}^{2}=0,94$

$\mathrm{Y}_{51 \mathrm{~cm}}=19,63-0,53 \mathrm{X}, \quad \mathrm{R}^{2}=0,88$

1 Y: teor de água; X: tempo de secagem

primeiras, presumivelmente, representaram segmento intermediário da segunda. Contudo, os tratamentos possibilitaram as condições necessárias às transferências de calor e de massa que redundaram em intensificação da evaporação da água das sementes.

$\mathrm{O}$ deslocamento do ar insuflado em secagens estacionárias pode ocasionar a manutenção ou mesmo a elevação do grau de umidade das sementes mais distanciadas da zona de entrada do ar aquecido e não atingidas pela frente de secagem. A chegada desta corresponde, aproximadamente, ao momento em que a elevação da temperatura e a redução do teor de água das sementes se acentuam. O caminhamento da frente de secagem, independentemente das temperaturas, foi alterado à medida que maiores fluxos de ar eram utilizados, o que confirma o descrito por Brooker et al. (1974) e Biagi et al. (1992). Como esperado, a velocidade de secagem reduziu- 
TABELA8. Variações (\%) entre os teores de água das sementes de soja nas distâncias de $17 \mathrm{~cm}$ e $51 \mathrm{~cm}$ durante secagens estacionárias conduzidas com diferentes fluxos e temperaturas do ar insuflado. Ponta Grossa, PR, 1995.

\begin{tabular}{cccccccc}
\hline \multirow{2}{*}{$\begin{array}{c}\text { Temperatura } \\
\left({ }^{\circ} \mathrm{C}\right)\end{array}$} & $\begin{array}{c}\text { Fluxo } \\
\left(\mathrm{m}^{3} / \text { minuto/t) }\right.\end{array}$ & 2 & 4 & 6 & 8 & 10 & 12 \\
\cline { 3 - 7 } & 26,9 & 3,2 & 6,5 & 7,1 & 8,7 & 8,8 & 5,2 \\
& 28,4 & 1,9 & 3,6 & 4,4 & 4,7 & 3,9 & 4,1 \\
& 33,2 & 2,9 & 3,9 & 4,6 & 3,5 & 2,4 & 5,6 \\
46 & 26,9 & 1,1 & 3,5 & 4,3 & 4,0 & 4,1 & 2,9 \\
& 28,4 & 1,6 & 5,1 & 4,7 & 4,9 & 5,7 & 4,1 \\
& 33,2 & 2,8 & 3,7 & 3,1 & 3,9 & 2,4 & 2,0 \\
50 & 26,9 & 2,2 & 4,9 & 6,1 & 6,2 & 5,5 & 5,3 \\
& 28,4 & 2,2 & 4,7 & 5,6 & 5,1 & 5,4 & 4,0 \\
& 33,2 & 2,6 & 3,8 & 4,0 & 3,8 & 2,4 & 3,4 \\
\hline
\end{tabular}

TABELA9. Velocidade média de secagem $\left(\% \mathrm{H}_{2} \mathrm{O} / \mathrm{h}\right)$ das sementes de soja nas três distâncias e média ponderada, após secagens estacionárias de 12 horas, conduzidas com diferentes fluxos e temperaturas do ar insuflado. Ponta Grossa, PR, 1995.

\begin{tabular}{cccccc}
\hline \multirow{2}{*}{$\begin{array}{c}\text { Temperatura } \\
\left({ }^{\circ} \mathrm{C}\right)\end{array}$} & $\begin{array}{c}\text { Fluxo } \\
\left(\mathrm{m}^{3} / \text { minuto/t }\right)\end{array}$ & 17 & 34 & 51 & Média \\
\cline { 3 - 5 } & 26,9 & 0,63 & 0,39 & 0,27 & 0,41 \\
& 28,4 & 0,68 & 0,48 & 0,33 & 0,48 \\
& 33,2 & 0,78 & 0,51 & 0,33 & 0,52 \\
& 26,9 & 0,65 & 0,57 & 0,32 & 0,49 \\
46 & 28,4 & 1,04 & 0,88 & 0,73 & 0,87 \\
& 33,2 & 0,63 & 0,46 & 0,47 & 0,52 \\
& 26,9 & 0,65 & 0,50 & 0,23 & 0,44 \\
50 & 28,4 & 0,74 & 0,51 & 0,45 & 0,56 \\
& 33,2 & 0,68 & 0,64 & 0,46 & 0,58 \\
\hline
\end{tabular}

se com a ampliação das distâncias das sementes do cilindro central.

As sementes de soja são consideradas produto rico em óleo e, portanto, com predominância de água tipo 3 (Biagi et al., 1992; Vertucci, 1993). Esse tipo de água, facilmente removido durante os processos de secagem, poderia estimular a aplicação de procedimentos de secagem rápida do produto. Todavia, secagens demasiadamente rápidas podem, nesse caso, provocar alterações que resultem em ruptura no tegumento e em tecidos embrionários, comprometendo o controle de permeabilidade das membranas celulares (França Neto, 1984). As velocidades de secagem constatadas mostraram-se superiores às citadas por McLean (1980) como passíveis de obtenção em equipamentos semelhantes. Tendo em vista os teores finais de água atingidos, a velocidade mínima de $0,44 \% \mathrm{H}_{2} \mathrm{O}$ /hora, proporcionada por todas as combinações fluxo-temperatura utilizadas, excetuada a de $26,9 \mathrm{~m}^{3} /$ minuto/t $\operatorname{com} 42^{\circ} \mathrm{C}$, mostrouse como a mais adequada para secagem de sementes de soja no período testado.

A uniformidade do processo de secagem apresenta relação direta com o fluxo de ar empregado (Brandenburg et al., 1961; Biagi et al., 1992). Pelas características inerentes ao modo como as sementes se comportam na secagem estacionária, verifica-se desuniformidade do teor de água entre sementes de 
diferentes distâncias à insuflação do ar aquecido, que diminui com a redução na espessura da massa (Brooker et al., 1974; McLean, 1980; Corrêa, 1981; Dalpasquale et al., 1987; Pasin, 1991).

As variações do teor de água entre pontos extremos da massa elevaram-se no transcurso da secagem até, aproximadamente, a oitava hora operacional, quando iniciaram tendência de redução. Fixadas as temperaturas, os valores encontrados foram sendo reduzidos, especialmente a $46^{\circ} \mathrm{C}$ e $50^{\circ} \mathrm{C}$, com o aumento do fluxo de ar, o que concorda com Brooker et al. (1974) e Biagi et al. (1992). Dentro de cada fluxo, as tendências decorrentes da elevação da temperatura foram variáveis ao longo do tempo de secagem; ao final da operação, o fluxo de $28,4 \mathrm{~m}^{3} /$ minuto/t não indicou efeitos da temperatura, enquanto os demais apresentaram os menores valores sob $46^{\circ} \mathrm{C}$. Nessas condições, verifica-se que a velocidade máxima de secagem, obtida com $28,4 \mathrm{~m}^{3} /$ minuto $/ \mathrm{t} \mathrm{e} 46^{\circ} \mathrm{C}$, trouxe o inconveniente do surgimento de gradientes superiores aos proporcionados, ao término do processo, por operações mais lentas. Por outro lado, todos os gradientes foram próximos aos encontrados em secagens semelhantes de sementes de arroz (Corrêa, 1981), de soja (Pasin, 1991) e de milho (Cavariani, 1996). Para McLean (1980), Dalpasquale et al. (1987) e Pasin (1991), os gradientes normalmente observados em secagens estacionárias não causam efeitos prejudiciais às sementes, uma vez que na descarga do secador ocorre mistura suficiente para uniformizar a distribuição da umidade pela massa.

\section{CONCLUSÃo}

$\mathrm{O}$ ar insuflado com fluxo de $28,4 \mathrm{~m}^{3} /$ minuto/t e temperatura de $46^{\circ} \mathrm{C}$ é, fisicamente, mais adequado para realização da secagem; o contrário sucede com fluxo de $26,9 \mathrm{~m}^{3} /$ minuto/t e temperatura de $42^{\circ} \mathrm{C}$.

\section{REFERÊNCIAS}

BAKER, K.D.; PAULSEN, M.R.; ZWEDEN, J.V. Hybrid and drying rate effects on seed corn viability.
Tansactions of the ASAE, v.34, n.2, p.499-506, 1991

BIAGI, J.D.; SILVA, I.J.O. Software para determinar as propriedades psicrométricas do ar. In: CONGRESSO BRASILEIRO DE ENGENHARIA AGRÍCOLA, 19., 1990, Piracicaba. Anais. Piracicaba: Sociedade Brasileira de Engenharia Agrícola, 1990. p.1161-1175.

BIAGI, J.D.; VALENTINI, S.R.; QUEIROZ, D.M. Secagem de produtos agrícolas. In: MAGALHÃES, P.S.G.; CORTES, L.A.B. (Coords.). Introdução à engenharia agrícola. Campinas: UNICAMP, 1992. cap.3, p.245-266.

BOUNOUS, E.B. Comparação de métodos de secagem em sementes de azevém anual (Lolium multiflorum L.). Pelotas: UFPel, 1986. 109p. Dissertação de Mestrado.

BOYD, A.H.; MATTHES, R.K.; WELCH, G.B. Heated air drying of soybean seed. Mississippi: Mississippi State University, 1974. 17p. (MAFES Journal, 2840)

BRANDENBURG, N.R.; SIMONS, J.W.; SMITH, L.L. Why and how seeds are dried. In: THE UNITED STATES DEPARTMENT OF AGRICULTURE. Seeds The Yearbook of Agriculture 1961. Washington: The United States Government Printing Office, 1961. p.295-306.

BRASIL. Ministério da Agricultura. Secretaria Nacional de Defesa Agropecuária. Regras para análise de sementes. Brasília, 1992. 365p.

BROOKER, D.B.; BAKKER-ARKEMA, F.W.; HALL, C.W. Drying cereal grains. Westport: AVI, 1974. $265 \mathrm{p}$

CARVALHO, N.M. A secagem de sementes. Jaboticabal: FUNEP, 1994. 165p.

CAVARIANI, C. Secagem estacionária de sementes de milho com distribuição radial do fluxo de ar. Piracicaba: USP-ESALQ, 1996. 85p. Tese de Doutorado.

CAVARIANI, C.; BAUDET, L.M.L. Secagem de sementes. Informe Agropecuário, v. 8, n.91, p.44-49, 1982.

CORRÊA, C.F. Secagem de sementes de arroz (Oryza sativa $\mathbf{L}$.) em silo secador com distribuição radial de ar. Pelotas: UFPel, 1981. 85p. Dissertação de Mestrado. 
DALPASQUALLE, V.A.; QUEIROZ, D.M.; PEREIRA, J.A.M.; SINÍCIO, R. Secagem de grãos em altas temperaturas. Viçosa: CENTREINAR, 1987.47p.

FRANÇA NETO, J.B. Qualidade fisiológica de sementes de soja. In: FRANÇA NETO, J.B.; HENNING, A.A Qualidades fisiológica e sanitária de sementes de soja. Londrina: Embrapa-CNPSo, 1984. p.1-24 (Embrapa-CNPSo. Circular técnica, 9).

HALL, C.W. Drying and storage of agricultural crops Westport: AVI, 1980. 382p.

HARRINGTON, J.F. Seed storage and longevity. In KOZLOWSKI, T.T. (Ed.). Seed biology. New York: Academic, 1972. v.3, p.145-245.

KREYGER, J. Practical observations on the drying of seed Seed Science and Technology, v.1, p.645-670, 1973

LASSERAN, J.C. Características técnicas dos secadores Revista Brasileira de Armazenamento, v.4, n.2, p.4-14, 1979.

McLEAN, K.A. Drying and combinable crops. Ipswich Farming, 1980. 280p.
PASIN, N.H. Secagem estática de sementes de soja. Informativo da Associação Brasileira de Tecnologia de Sementes, v.2, n.1, p.33-39, 1991

SILVA, J.S.; LACERDAFILHO, A.F.; DALPASQUALE, V.A. Métodos de secagem e secadores. Informe Agropecuário, v.9, n.99, p.3-5, 1983.

VEGA, C.R. Efeito do método de secagem sobre a qualidade das sementes de arroz (Oryza sativa L.). Pelotas: UFPel, 1989. 123p. Dissertação de Mestrado.

VERTUCCI, C.W. Predicting the optimum storage conditions for seeds using thermodynamic principles. Journal of Seed Tecnology, v.17, n.2, p.41-53, 1993.

VILLELA, F.A. Efeitos da secagem intermitente sobre a qualidade de sementes de milho. Piracicaba: USP-ESALQ, 1991. 104p. Tese de Doutorado.

WESTERMAN, P.W.; WHITE, G.M.; ROSS, I.J. Relative humidity effect on the high-temperature drying of shelled corn. Transactions of the ASAE, v.16, n.6, p.1136-1139, 1973

ZIMMER, G.J. Seca-aeração para sementes de arroz. Pelotas: UFPel, 1989. 70p. Dissertação de Mestrado. 